Розглядаеться рішення задачі рачіональної організачії вагонопотоків на полігоні виділених технічних станцій залізниці з використанням методики вирішення задачі про ранець за допомогою функиій множини. Пропонується всі множини змінних задач лінійного програмування в термінах булевих змінних звести до звичайної оптимізачії за множниками Лагранжа. Це дозволяє істотно адаптувати задачу вектор ної оптимізації до задач раціональної організачії вагонопотоків

Ключові слова: задача про ранець, функиіл безлічі, векторна оптимізація, організація вагонопотоків, енергоефективність перевезень

Рассматривается решение зада чи ращиональной организачии вагонопотоков на полигоне выделенных технических станиий железной дороги с использованием методики решения задачи о ранще с помощью функиий множества. Предлагается все множество переменных задач линейного программирования в терминах булевых переменных свести $\kappa$ обычной оптимизащии по множителям Лагранжа. Это позволяет существенно адаптировать задачи векторной оптимизачии $к$ задачам рациональной организации вагонопотоков

Ключевые слова: задача о ранце, функция множества, векторная оптимизация, организащия вагонопотоков, энергоэффективность перевозок

\section{Introduction}

Railroad transport is currently functioning under extremely difficult conditions. A decrease in the volumes of freight transportation has led to closing some low-performing stations, and, accordingly, to a change in the structure and direction of wagon flows from consignors to consignees.

Instability of economic processes in the organization of transportation reduces the level of energy efficiency of rail transport operations. At the same time, in terms of consumption of fuel and energy resources per unit of a delivered article, railroad transport that performs the vast majority of transportation volumes in the state is the most cost-efficient. From the point of view of energy saving, there exists a huge reserve in the optimization of energy consumption, both by the railroad transport and by infrastructure units, related in one way or another to transportation. The main direction of
UDC 656.225.001.57

DOI: $10.15587 / 1729-4061.2017 .111940$

\title{
A NEW METHOD FOR SOLVING THE PROBLEM ON THE ORGANIZATION OF WAGON FLOWS UNDER CONDITION OF ENERGY EFFICIENCY OF TRANSPORTATION
}

\author{
O. Papakhov \\ $\mathrm{PhD}$, Associate Professor* \\ E-mail: papahova0362@gmail.com \\ N. Logvinova \\ $\mathrm{PhD}$, Associate Professor* \\ E-mail: logvinovanata1987@gmail.com \\ O. K h a r che n k o \\ $\mathrm{PhD}$, Associate Professor* \\ E-mail: olesiakh100@gmail.com \\ A. Mily a $\mathbf{n} \mathbf{c} \mathbf{h}$ \\ $\mathrm{PhD}$ \\ Department of operational management \\ Lviv Branch of Dnipropetrovsk \\ National University of Railway Transport \\ named after Academician V. Lazaryan \\ I. Blazhkevych str., 12a, Lviv, Ukraine, 79052 \\ E-mail: milyan744@ukr.net \\ V. S i chenko \\ Doctor of Technical Sciences, Professor** \\ E-mail: elpostz@i.ua \\ *Department of operational management*** \\ **Department of Intellectual power supply systems $* * *$ \\ $\star \star \star$ Dnipropetrovsk National University of Railway \\ Transport named after Academician V. Lazaryan \\ Lazaryana str., 2, Dnipro, Ukraine, 49010
}

activities aimed at reducing consumption of energy resources is to improve structures in the infrastructure, power supply systems and rolling stock, as well as methods of control over the motion of trains.

In order to organize wagon flows in the railroad network, a plan of freight train formation is calculated, which is based on the modifications of the network configuration, technological equipment of sections and stations, traction means and capacity of electricity supply system.

Given various factors that affect calculation of the train formation plan, as well as intentions of carrier companies to optimize the motion of their wagons, it is possible to argue about the relevance of the issue on rationalization of the organization of wagon flows in order to improve energy efficiency of transportation. In other words, there is a need to devise a procedure for solving a problem on the organization of wagon flows, which would make it possible to determine 
the optimal variant for handling wagons at technical stations, as well as to direct wagon flows by the most promising destinations.

\section{Literature review and problem statement}

Many scientific methods were proposed in order to improve the system of organization of wagon flows on railroads. For example, authors of paper [1] propose to improve a system of organization of wagon flows by considering a combination of a larger number of related routes in the formation plan, by searching and accounting for of a larger number of influencing factors, consideration of financial efficiency by reducing a wagon's turnover.

In article [2], it was noted that the improvement in competitiveness of railroads in Spain is carried out by seeking new routes for the motion of cargoes. These approaches enable solving a task on the organization of wagon flows only as a single-criterion problem.

Paper [3] describes a method for calculating the optimal multiphase routes for the motion of wagons. The paper in fact addresses complex problems on linear programming of the transportation type. The method to tackle these problems is a method of their reduction to the task on constructing a minimum cost flow in an appropriate transportation network.

Authors of article [4] proposed a new method for solving the knapsack type problems, which makes it possible to refuse the Boolean variables and to solve a basic optimization problem employing the Lagrange multipliers. The method proposed allows significant adaptation of the problems on vector optimization to the problems of rational organization of wagon flows with constraints for the handling capacity of technical stations and the throughput of sections.

In the consideration of improving the effectiveness of management, there is always a problem of rational investment. In mathematical terms, this problem is known as the knapsack problem (backpack). A detailed overview of these problems is given in paper [5] that tackles the problem with multiple knapsack.

Article [6] should be noted, which proposed an approach for determining a rational ratio between the components of the investment process - volume of investment, profitability, and the time of implementation of particular projects.

Based on an analysis of the scientific literature, we can say that when designing an algorithm in order to solve a problem on selecting the optimal plan of train formation, it is necessary to determine:

- organization of conducting a given calculation;

- procedure for collection and preparation of initial data;

- procedure for selecting rational variants, making the final decision, and assignment of tasks for railroads and stations.

Mathematical approaches proposed in the considered sources make it possible to apply interactive methods to solve a multicriteria problem. These methods construct a subjective utility function, reflecting the actual state of affairs in the polygon at selected railroad stations, rather than a formal model of reduced costs. That is why the statement and the solution of the problem on the rational organization of wagon flows considering the improvement of energy efficiency of transportation as a multicriteria one will make it possible to better account for various aspects in the organization of wagon flows.

Paper [7] considers a well-known combinatorial optimization problem of a single criterial knapsack with a wide range of applications. This paper deals with the problem of an integer multiple criterion of knapsack (MCKP), explores basic MCKP and its more complex extensions, including binary variables, multiple constraints, and time-dependent criterion functions. It was proposed a comprehensive program DP-framework, which is capable of solving a wide range of problems using the knapsack models that represent uncertainty, or are dependent on time constraints. The continuation of this research area might include effective implementation of the proposed DP approaches.

Authors of article [8], to solve multi-purpose knapsack problems, proposed an approach based on dynamic programming. The main idea of this approach is based on using several complementary relations of domination, in order to reject partial solutions that cannot lead to the emergence of new non-directed vectors of the optimization criterion. An effective method is thereby obtained, which is superior to existing methods, both in terms of the utilization of CPU time and the dimension of the solved multicriteria problems. The article provides data from extensive numerical experiments for different types of cases. A comparison with other precise methods is also included. In addition, for the first time, the solution to the problem with three complementary relationships of domination is presented.

One should note paper [9], which addresses two categories of optimization methods with multiple triggers: procedures based on memory and without memory. The former are based on the identification and recording of specific types of information (attributes) for use in the future optimization. The latter are based on the sample order statistics and the generation of disjoint outcomes. The interaction between functions of these two categories constitutes a promising area for the future research into optimization.

The application of mathematical modeling methods when building a route of wagon flows in trains in a polygon at the stations is addressed in [10]. The author proposed to change the pre-routing of wagons on the railroads of China and to optimize a standard plan of train formation. To reduce the complexity of the problem, this article suggests a nonlinear binary programming of the model to improve the integrated plan of train formation. The proposed model comprehensively examines various operational requirements to the calculation of freight train formation plan taking into account the throughput constraints of spans between stations, but it does not consider own limitations for the handling capacity of train formation stations and its road development.

Based on an analysis of the scientific literature, it became clear that at all the variety of techniques to solve the knapsack type problems and the areas of their application, there is a possibility to employ this class of problems for the rational organization of wagon flows in trains using a function of the set and vector optimization.

\section{The aim and objectives of the study}

The aim of present study is the adaptation of a method for solving the knapsack problem using a function of the set to 
determining the rational organization of wagon flows in trains in order to improve energy efficiency of transportation.

To achieve the set aim, the following tasks have to be solved:

- to adapt the proposed method for solving knapsack-type problems to a normal optimization problem by the Lagrange multipliers by eliminating the Boolean variables;

- to apply the adapted method and developed software for solving knapsack-type problems under conditions of a rational system of the organization of wagon flows in a polygon at the selected railroad stations;

- to prove adequacy of the proposed algorithm and to confirm correctness of mathematical notation of the solution to knapsack type problems in order to apply it for the rational organization of wagon flows to improve energy efficiency of transportation.

\section{Procedure and solution to the knapsack problem in terms of set functions in the rational organization of wagon flows}

\section{1. Procedure of the knapsack problem in terms of} set functions

Set functions. Let $\Omega$ be a certain set, and $\boldsymbol{\aleph}(\Omega)$ is a set of subsets of the set $\Omega$, which has the following properties:

1. If $A$ and $B$ belong to $\mathrm{N}(\Omega)$, then their union is

$A \cup B \in \boldsymbol{\aleph}(\Omega) ;$

2. If $A$ and $B$ belong to $\mathrm{\aleph}(\Omega)$, then their difference is

$$
A \backslash B \in \aleph(\Omega) ;
$$

3. The set $\Omega$ itself also belongs to $\mathrm{\aleph}(\Omega)$.

In other words, set $\boldsymbol{\kappa}(\Omega)$ is algebra.

Definition 1. Mapping $\boldsymbol{\kappa}(\Omega)$ onto a valid axis $R$ according to some rule $F$ will be called the set function. Among the various functions of the set, we shall select the one that has the following properties:

1. $\forall A \in \mathfrak{N}(\Omega) \rightarrow \mu(A) \geq 0$;

2. $\mu(A)=0$, if and only if $A=\varnothing$;

3. $\mu(A \cup B)=\mu(A)+\mu(B)-\mu(A \cap B)$;

4. If $\left\{B_{n}\right\}, n=1,2 \ldots$ is some sequence approaching $B$, then

$$
\lim _{n \rightarrow \infty} \mu\left(B_{n}\right)=\mu(B) \text {. }
$$

Definition 2. Function $\mu(A)$, which has the specified properties, will be called a measure for $\mathrm{\kappa}(\Omega)$.

Derivative from the set function for measure [7]

If we have a sequence $\left\{B_{n}\right\}, \quad n=1,2 \ldots$, each element of which belongs to $\mathbf{\aleph}(\Omega), F(A)$ is the set function, then a sequence of the following numbers is considered

$$
a_{n}=\frac{F\left(A \Delta B_{n}\right)-F(A)}{\mu\left(A \Delta B_{n}\right)-\mu(A)},
$$

where $\Delta$ is the operation of symmetric difference of two sets.

Definition 3. If there is a $\operatorname{limit} \lim a_{n}=a$, then this limit is called a derivative from the set function $F(A)$ for measure $\mu$ on sequence $\left\{B_{n}\right\}, n=1,2 \ldots$ and is denoted in the form:

$$
\left.\frac{d F(A)}{d \mu}\right|_{\left\{B_{n}\right\}} \triangleq
$$

Paper [7] proved a theorem of the existence of this derivative at a converging sequence $\left\{B_{n}\right\}$, if function $F(A)$ is continuous, that is, there the following takes places

$$
\lim _{n \rightarrow \infty} F\left(A_{n}\right)=F(A)
$$

where sequence $\left\{A_{n}\right\}$ is arbitrary, converging to $A$, and then the following takes place

$$
\left.\frac{d F(A)}{d \mu}\right|_{\left\{B_{n}\right\} \rightarrow B}=\frac{F\left(A \Delta B_{n}\right)-F(A)}{\mu\left(A \Delta B_{n}\right)-\mu(A)} .
$$

Theorem [7]. If $A_{*} \in \mathfrak{N}(\Omega)$, is such that $F\left(A_{*}\right) \leq F(A)$ for every $A \in \mathfrak{N}(\Omega)$ and there exists a derivative, then

$$
\left.\frac{d F(A)}{d \mu}\right|_{\left\{B_{n}\right\} \rightarrow B \subseteq A_{*}} \leq 0 .
$$

Thus, condition (3) is necessary for determining the set $A_{*}$, at which the set function assumes the minimum value.

The Lagrange method for set functions.

The main method for solving the problems on conditional extremum is the Lagrange method.

In a general case, a problem on the conditional extremum, in terms of set functions, is

$$
F(A) \rightarrow \min
$$

under condition $A \in U=\left\{A \in \aleph(\Omega): G_{i}(A) \leq 0, i=\overline{1, m}\right\}$.

The Lagrange function takes the form

$$
L(A, \lambda)=F(A)+\sum_{i=1}^{m} \lambda_{i} G_{i}(A) .
$$

We shall demonstrate that there are such $\lambda_{i}^{*} \geq 0$, that problem (10) is reduced to finding a minimum of the Lagrange function (5).

Definition. The pair $\left\langle A_{*}, \lambda^{*}\right\rangle$ is called a saddle pair of the Lagrange function, if there is

$$
L\left(A_{*}, \lambda\right) \leq L\left(A_{*}, \lambda^{*}\right) \leq L\left(A, \lambda^{*}\right),
$$

Lemma. The pair $\left\langle A_{*}, \lambda^{*}\right\rangle$ is the saddle pair when and only when

$$
\begin{aligned}
& L\left(A_{*}, \lambda^{*}\right) \leq L\left(A, \lambda^{*}\right), \\
& \lambda_{i}^{*} G_{i}\left(A_{*}\right)=0, i=\overline{1, m}, A_{*} \in U .
\end{aligned}
$$

Theorem. If the pair $\left\langle A_{*}, \lambda^{*}\right\rangle$ is the saddle pair of the Lagrange function, it is the solution to problem (4).

Proof. Lemma. Necessity

Let the pair $\left\langle A_{*}, \lambda^{*}\right\rangle$ belong to $\aleph(\Omega) \times \Lambda$, where

$$
\Lambda=\left\{\lambda_{1}, \lambda_{2}, \ldots, \lambda_{m}: \lambda_{i} \geq 0, i=\overline{1, m}\right\}
$$

then relation (7) represents the right-hand inequality (6). To obtain (8), we shall change the left-hand inequality (6) considering the Lagrange function:

$$
F\left(A_{*}\right)+\sum_{i=1}^{m} \lambda_{i} G_{i}\left(A_{*}\right) \leq F\left(A_{*}\right)+\sum_{i=1}^{m} \lambda_{i}^{*} G_{i}\left(A_{*}\right)
$$

and we obtain 


$$
\sum_{i=1}^{m}\left(\lambda_{i}^{*}-\lambda_{i}\right) G_{i}\left(A_{*}\right) \geq 0
$$

We shall put $\lambda_{i}=\lambda_{i}^{*}+1$, in this inequality, the rest is

$$
\lambda_{j}=\lambda_{j}^{*}
$$

then we have

$$
-G_{i}\left(A_{*}\right) \geq 0
$$

from which we obtain $G_{i}\left(A_{*}\right) \leq 0$. Due to arbitrariness of $i$, we have $A * C$, which proves necessity.

Sufficiency. Let the pair $\left\langle A_{*}, \lambda^{*}\right\rangle \in \aleph(\Omega) \times \Lambda$ and relations (7) and (8) are satisfied. We shall demonstrate that this pair is the saddle one. From (7), the right-hand inequalities (6) follow, while it follows from condition (8) that $A_{*} \subset U$, that is, $G_{i}\left(A_{*}\right) \geq 0$, but $\lambda_{i}^{*}=0$, that is, we have (9).

We obtain from (9)

$$
\left(\lambda_{i}^{*}-\lambda_{i}\right) G_{i}\left(A_{*}\right)=-\lambda_{i} G_{i}\left(A_{*}\right) \geq 0
$$

for all $\lambda_{i} \geq 0$, for which $G_{i}\left(A_{*}\right)<0$.

By adding the inequalities obtained, we have

$$
\sum_{i=1}^{m}\left(\lambda_{i}^{*}-\lambda_{i}\right) G_{i}\left(A_{*}\right) \geq 0
$$

for all $\lambda \in \Lambda$ or

$$
\sum_{i=1}^{m} \lambda_{i} G_{i}\left(A_{*}\right) \leq \sum_{i=1}^{m} \lambda_{i}^{*} G_{i}\left(A_{*}\right) .
$$

By adding $F\left(A_{*}\right)$ to both parts of this inequality, we obtain the left-hand side of (4), which finalizes proving the lemma.

The proof the theorem. We have from condition (8) $A_{*} \subset U$, that is, constraints (4) are met.

Since $L\left(A_{*}, \lambda^{*}\right)=F\left(A_{*}\right)$, inequality (7) is accepted in the form

$$
F\left(A_{*}\right)=L\left(A_{*}, \lambda^{*}\right) \leq F(A)+\sum_{i=1}^{m} \lambda_{i}^{*} G_{i}(A)
$$

considering

$$
\sum_{i=1}^{m} \lambda_{i}^{*} G_{i}(A) \leq 0
$$

we obtain $F\left(A_{*}\right) \leq F(A)$ at all $A \subset U$, which proves the theorem.

Thus, the aforesaid confirms applicability of the Lagrange method to the problems on conditional extremum, formed in terms of set functions.

Next, we shall consider a procedure for solving the knapsack problem using the theory of functions of sets.

\section{2. A knapsack problem in terms of set functions}

Formal notation of the knapsack problem takes the form

$$
\sum_{j=1}^{n} c_{j} x_{j} \rightarrow \max
$$

under condition

$$
\sum_{j=1}^{n} a_{j} x_{j} \leq b
$$

where $x_{j} \in\{0,1\}, j=\overline{1, n}$.

Let the set $A$ in problem (10), (11) be determined as

$$
A=\left\{j: x_{j}=1, j=\overline{1, n}\right\},
$$

then this problem can be recorded in the form

$$
\begin{aligned}
& F(A)=\sum_{j \in A} c_{j} \rightarrow \max ; \\
& G(A)=\sum_{j \in A} a_{j}-b .
\end{aligned}
$$

The Lagrange function is as follows

$$
L(A, \lambda)=-F(A)+\lambda G(A) .
$$

If $A_{*}$ delivers a minimum of the Lagrange function, then, considering (3), we shall obtain

$$
\begin{aligned}
& \left.\frac{d L\left(A_{*}, \lambda\right)}{d \mu}\right|_{\left\{B_{n}\right\} \rightarrow B \subseteq A *}= \\
& =-\sum_{j \in B} c_{j}+\left.\lambda\left(\sum_{j \in B} a_{j}\right)\right|_{B=\{j\}}=-c_{j}+\lambda a_{j} \leq 0,
\end{aligned}
$$

hence, we obtain

$$
A_{*}(\lambda)=\left\{j:-c_{j}+\lambda a_{j} \leq 0\right\} .
$$

Since $c_{j}$ and $a_{j}>0$, then the set $A_{*}(\lambda)$ can be recorded in the form

$$
A_{*}(\lambda)=\left\{j: \lambda \leq \frac{c_{j}}{a_{j}}\right\} .
$$

For the formation algorithm of set $A$, it is required to order the set $\{j: j=\overline{1, n}\}$ by ratio

$$
\frac{c_{j}}{a_{j}} \geq \frac{c_{j+1}}{a_{j+1}}, \quad j=\overline{1, n-1} .
$$

It includes such $j$, in which relations $\frac{c_{j}}{a_{j}}$ are the largest. Paper [8] terms this algorithm as heuristic, but, as can be seen from the above, this algorithm is required to solve the knapsack problem.

If at some $j$ we have

$$
\sum_{i=1}^{j} a_{i}<b,
$$

then some elements in set $A$ should be replaced with $i>j$.

Let us consider a multidimensional knapsack problem when

$$
F(A)=\sum_{j \in A} c_{j} \rightarrow \max
$$

under conditions 


$$
\sum_{j \in A} a_{i j} \leq b_{i}, \quad i=\overline{1, m}
$$

In this problem, the necessary condition takes the form

$$
A=\left\{j:-c_{j}+\sum_{i=1}^{m} \lambda_{i} a_{i j} \leq 0\right\},
$$

where $\lambda_{i}$ are the Lagrange multipliers.

It is obvious that this set significantly depends on the Lagrange multipliers

$$
\lambda=\left\{\lambda_{i} \geq 0, i=\overline{1, m}\right\}
$$

Sorting the Lagrange multipliers so that there is

$$
A(\lambda)=\left\{j:-C_{j}+\sum_{i=1}^{m} \lambda_{i} a_{i j} \leq 0, \sum_{j \in \Lambda} a_{i j} \leq b_{i}, i=\overline{1, m}\right\},
$$

we obtain a possibility to determine function $F(A)$ via Lagrange multipliers and then we come to the problem of finding a maximum of function $F(A(\lambda))$ by the Lagrange multipliers.

Thus, a knapsack problem is reduced to finding a normal maximum $F(A(\lambda))$, which is determined algorithmically.

Example. It is required to find such a set $A \subseteq\{1,2, \ldots n\}$, so that

$$
F_{1}(A)=\sum_{j \in A} f 1(j) \rightarrow \max
$$

under conditions

$$
\begin{aligned}
& F_{2}(A)=\sum_{j \in A} f 2(j) \geq m 2 ; \\
& F_{3}(A)=\sum_{j \in A} f 2(j) \geq m 3 .
\end{aligned}
$$

In this example, $n=5$, and $f 1, f 2, f 3$ represent

$$
\begin{aligned}
& f 1=[15,7,8,5,10] ; \\
& f 2=[20,5,6,7,3] ; \\
& f 3=[6,2,2,5,4] .
\end{aligned}
$$

By sorting using the Lagrange multipliers, we obtain

$$
A=\{13\} ; \quad F_{1}=23 ; \quad F_{2}=26 ; \quad F_{3}=8 .
$$

In order to test, we shall perform a search for all subsets of set $\{1,2,3,4,5\}$, and we obtain the same result.

Software in the Maple environment, which implements the algorithm in question, produces the following:

$>$ restart:with(linalg):with(combstruct):

$>\mathrm{n}:=5$;

$\mathrm{n}:=5$

$>\mathrm{w}:=\{\operatorname{seq}(\mathrm{i}, \mathrm{i}=1 . . \mathrm{n})\}$;

$w:=\{1,2,3,4,5\}$

$>$ AA:=allstructs(Subset(w));

$A A:=\{\{2,3,4,5\},\{3,4,5\},\{1,3,4,5\},\{4,5\},\{1,4,5\},\{2,4,5\}$, $\{1,2,4,5\},\{5\},\{1,5\},\{2,5\},\{1,2,5\},\{3,5\},\{1,3,5\},\{2,3,5\}$, $\{1,2,3,5\},\{1\},\{2\},\{1,2\},\{3\},\{1,3\},\{2,3\},\{1,2,3\},\{4\},\{1,4\},\{2,4\}$, $\{1,2,4\},\{3,4\},\{1,3,4\},\{2,3,4\},\{1,2,3,4\},\{1,2,3,4,5\},\{\}\}$

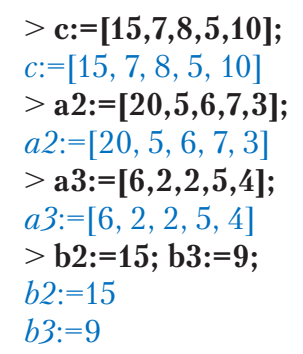

$>$ F1max:=0:for $t 1$ from 0 by 0.1 to 20 do for $t 2$ from 0 by 0.1 to 30 do $A:=\{\}$ :for $i$ from 1 to $n$ do $f:=-c[i]-$ $\mathrm{t} 1{ }^{*} \mathrm{a} 2[\mathrm{i}]+\mathrm{t} 2 * \mathrm{a} 3[\mathrm{i}]:$ if $\mathrm{f}<=0$ then $\mathrm{A}:=\mathrm{A}$ union $\{\mathrm{i}\}$ :end if:end do:C:=0:F2:=0:F3:=0:for $\mathrm{z}$ in A do $\mathrm{C}:=\mathrm{C}+\mathrm{C}[\mathrm{z}]: \mathrm{F} 2:=\mathrm{F} 2+\mathrm{a}$ 2[z]:F3: $=F 3+a 3[z]$ end do:if $F 2>=b 2$ and $F 3<=b 3$ then if F1 max $<$ C then F1max:=C:Amax:=A:F2max:=F2:F3max:=F3:end if: end if: end do: end do:print(t1,t2,F1max,F2max,F3max,Amax);

$20.1,30.1,23,26,8,\{1,3\}$

$>$ for $\mathrm{z}$ in AA do $\mathrm{A}:=\{\}$ :for $\mathrm{j}$ in $\mathrm{z}$ do $\mathrm{f}:=-\mathrm{c}[\mathrm{j}]-\mathrm{t} 1 * \mathrm{a} 2[-$ $\mathrm{j}]+\mathrm{t} 2 * \mathrm{a} 3[\mathrm{j}]:$ if $\mathrm{f}<=0$ then $\mathrm{A}:=\mathrm{A}$ union $\{\mathrm{j}\}$ :end if: end do: $C:=0: F 2:=0: F 3:=0:$ for $i$ in $A$ do $C:=C+c[i]: F 2:=F 2+a 2$ [i]:F3:=F3+a3[i]: end do:if $F 2>=b 2$ and F3<=b3 then print(z,A,C,F2,F3): end if: end do:
$\{1,3,4,5\},\{1,3\}, 23,26,8$
$\{1,4,5\},\{1\}, 15,20,6$
$\{1,2,4,5\},\{1,2\}, 22,25,8$
$\{1,5\},\{1\}, 15,20,6$
$\{1,2,5\},\{1,2\}, 22,25,8$
$\{1,3,5\},\{1,3\}, 23,26,8$
$\{1\},\{1\}, 15,20,6$
$\{1,2\},\{1,2\}, 22,25,8$
$\{1,3\},\{1,3\}, 23,26,8$
$\{1,4\},\{1\}, 15,20,6$
$\{1,2,4\},\{1,2\}, 22,25,8$
$\{1,3,4\},\{1,3\}, 23,26,8$

The result of software execution in the Maple environment is the answer: $A=\{13\} ; F_{1}=23 ; \quad F_{2}=26 ; \quad F_{3}=8$.

When comparing results of solving the set problem performed by sorting all subsets of set $\{1,2,3,4,5\}$ using the Lagrange multipliers and by applying software in the Maple environment, the answer is similar. The result obtained allows us to confirm the adaptation of the algorithm for solving vector optimization problems to solving the problems on the rational use of resources.

\section{Discussion of results of solving a knapsack problem} and its practical significance

Our work proposes a method for solving the knapsack-type problems. The method enables, in contrast to existing techniques, abandoning Boolean variables and makes it possible to solve a basic optimization problem employing the Lagrange multipliers. The proposed method allows adaptation of the algorithm for solving a vector optimization problem to the problems on the rational use of resources. The method proposed outperforms those existing by reducing the time of using computer processor.

We proved applicability of the Lagrange method to the problems on a conditional extremum in terms of set functions. The necessary conditions for solving vector optimization problems are defined.

A result of the study is the developed algorithm for solving the knapsack problems without using differentiation 
operations, implemented to solve a problem on the rational organization of wagon flows. By reducing the complexity of the problem, it has become possible to employ this algorithm when designing an automated work place (AWP) for an engineer responsible for planning the formation of trains.

It should be specially noted that a reduction of the time needed to solve a problem makes it possible to timely adjust the plan of freight trains formation, to eliminate a lot of irrational variants when handling wagons at technical stations. The proposed algorithm helps identify variants to direct train flows to the most promising destinations at minimal energy cost for transportation.

Limitations of the proposed approach include a closed cycle of loaded wagons routes and part of these routes traveled unloaded until the next loading. In some cases, there is a need to change a weight of the train composition, associated with fractures of weight, and, therefore, a change in the balance between wagon flows and train flows.

\section{Conclusions}

1. We devised a method for solving a knapsack-type problem that makes it possible to solve a basic optimization problem employing the Lagrange multipliers. Its special feature is the rejection of Boolean variables. In contrast to existing techniques, it enables significant adaptation of vector optimization problems to the problems on the rational use of resources, including investment.

2. The proposed method makes it possible to adapt the algorithm for solving a vector optimization problem to the rational system of organization of wagon flows in trains, leading to greater energy efficiency in railroad transportation.

3. We confirmed correctness of the mathematical notation of solution to a knapsack-type problem and proved adequacy of the proposed algorithm, as well as adapted it for adjusting a plan of freight trains formation in order to improve energy efficiency of transportation.

\section{References}

1. Mazurenko, O. O. Efficiency of formation of two-group trains in operative conditions of organization of carriages [Text] / O. O. Mazurenko, A. V. Kudryashov // Collection of scientific works of the State Research and Production Enterprise «Transport systems and technologies of transportation». - 2014. - Issue 7. - P. 50-55.

2. González, E. M. Analysis and Viability of Railway Exportation to Europe from the South of Spain [Text] / E. M. González, G. G. Sánchez, J. M. M. Romero // Procedia - Social and Behavioral Sciences. - 2014. - Vol. 160. - P. 264-273. doi: 10.1016/j. sbspro.2014.12.138

3. Baushev, A. N. Mathematical model of multiphase railroad cargo transportation [Text] / A. N. Baushev, A. T. Osminin, L. A. Osminin // Mathematical modeling. - 2013. - Vol. 25, Issue 10. - P. 108-122.

4. Papakhov, A. Yu. Use of the set-function method for the rational organization of car-stream flows [Text] / A. Yu. Papakhov // Transport systems and transport technologies. - 2016. - Issue 12. - P. 69-74.

5. Reznikov, A. E. Mathematical Models and Algorithms for Solving the Problems of Optimal Loading of Vehicles [Text] / A. E. Reznikov, A. N. Fedorin // In Sat. tr. 11th International Scientific and Industrial Forum "Great Rivers". ICEF. Problems and prospects of development of educational, scientific and innovative transport complexes. - Nizhniy Novgorod, 2009.

6. Myamlin, S. V. Upgrading of economic simulation methods for increasing efficiency of investments [Text] / S. V. Myamlin, K. V. Zhyzhko // Science and Transport Progress. Bulletin of Dnipropetrovsk National University of Railway Transport. - 2014. Issue 6 (54). - P. 34-41. doi: 10.15802/stp2014/32656

7. Klamroth, K. Dynamic Programming Approaches to the Multiple Criteria Knapsack Problem [Text] / K. Klamroth, M. M. Wiecek. - Clemson University Clemson, SC USA, 2015. - 30 p.

8. Bazgan, C. An Efficient Implementation for the 0-1 Multi-objective Knapsack Problem. Vol. 4525 [Text] / C. Bazgan, H. Hugot, D. Vanderpooten // Lecture Notes in Computer Science. - Springer, 2007. - P. 406-419. doi: 10.1007/978-3-540-72845-0_31

9. Beausoleil, R. P. Multi-start and path relinking methods to deal with multiobjective knapsack problems [Text] / R. P. Beausoleil, G. Baldoquin, R. A. Montejo // Annals of Operations Research. - 2007. - Vol. 157, Issue 1. - P. 105-133. doi: 10.1007/s10479007-0199-8

10. Lin, B. Integrating car path optimization with train formation plan: a non-linear binary programming model and simulated annealing based heuristics [Electronic resource] / B. Lin // arXiv. - 2017. - Available at: https://arxiv.org/ftp/arxiv/papers/1707/1707.08326.pdf

11. Bosov, A. A. Functions of sets and their application [Text] / A. A. Bosov. - Dneprodzerzhinsk: Izd. House "Andrew", 2007. - 182 p.

12. Lazorev, A. A. Theory of schedules. Tasks and algorithms [Text] / A. A. Lazorev, E. R. Gafarov. - Moscow: Publishing House of Moscow State University. M. V. Lomonosov, 2011. - 222 p. 